\title{
Sex Differences in the Effects of Weight Reduction on Future Blood Pressure Elevation in a Mildly Obese Middle-Aged Population
}

\author{
Shin Kawasoe, MD, PhD; Takuro Kubozono, MD, PhD; Satoko Ojima, MD; \\ Takeko Kawabata, MD; Hironori Miyahara, MD, PhD; \\ Koichi Tokushige, MD, PhD; Mitsuru Ohishi, MD, PhD
}

\begin{abstract}
Background: The effectiveness of weight loss (WL) in preventing blood pressure (BP) elevation is common knowledge; however, the effect of sex differences is not known.

Methods and Results: Health checkup data from Kagoshima Kouseiren Medical Healthcare Center for middle-aged participants (40-49 years old) with mild obesity (body mass index [BMI] 25.0-29.9 kg/ $/ 2$ ) who had examination data for 2 follow-up time-points (after 3 and 10 years) were analyzed. Propensity score (PS) matching using data from the first examination was used to match participants with a decrease in $\mathrm{BMI} \geq 1.0 \mathrm{~kg} / \mathrm{m}^{2}$ at 3 years (WL group) with those with a BMI decrease $<1.0 \mathrm{~kg} / \mathrm{m}^{2}$ or weight gain (non-WL group). BP values were compared after 3 and 10 years between the 2 groups, as was the prevalence of hypertension after 10 years. PS matching resulted in 232 men and 160 women in each group. Among women, systolic BP (SBP) and hypertension prevalence after 10 years were significantly lower in the WL than non-WL group $(P<0.01$ and $P<0.05$, respectively). There were no significant differences in SBP and hypertension prevalence after 10 years in men in the 2 groups.
\end{abstract}

Conclusions: There were sex differences in the effectiveness of WL in preventing future BP elevation in mildly obese middle-aged participants: WL prevented future BP elevation and hypertension onset in women, but not in men.

Key Words: Blood pressure elevation; Obesity; Sex difference; Weight loss

$\mathbf{H}$ ypertension is a well-known risk factor for cardiovascular disease morbidity and mortality; thus, the development of hypertension needs to be prevented to avoid cardiovascular diseases. ${ }^{1,2}$ The association between obesity and hypertension has been extensively researched and confirmed. Weight gain increases blood pressure (BP);3,4 conversely, weight loss (WL) reduces the $\mathrm{BP}$ or suppresses its elevation..$^{\mathbf{5}, \mathbf{6}}$ Therefore, WL through exercise and lifestyle improvement is recommended as one of the first-line therapies for hypertension. ${ }^{7,8}$

The World Health Organization defines obesity as a body mass index (BMI) $\geq 30.0 \mathrm{~kg} / \mathrm{m}^{2}$. In Japan, the proportion of individuals with a BMI $\geq 30 \mathrm{~kg} / \mathrm{m}^{2}$ is $2.2 \%$ for men and $3.5 \%$ for women, ${ }^{9}$ which is lower than in Western countries. However, individuals with a BMI of $26-28 \mathrm{~kg} / \mathrm{m}^{2}$ are reported to have high odds ratios for developing hyperglycemia, hypertension, and dyslipidemia. ${ }^{10}$ Japanese people are likely to develop health problems even though they are mildly overweight. Focusing on this point, the Japan Society for the Study of Obesity defines a BMI $\geq 25 \mathrm{~kg} / \mathrm{m}^{2}$ as obese for the Japanese population.

Many studies have reported on the importance of WL in preventing BP elevation. However, sex differences in the effects of WL on increases in BP have not been adequately elucidated. In the Japanese population, the prevalence of hypertension increases with age in both men and women. ${ }^{11}$ The proportion of obesity by age differs between men and women. In men, the prevalence of obesity peaks for those aged in their $40 \mathrm{~s}$ and then gradually decreases. In women, the prevalence of obesity increases consistently until the seventh decade. ${ }^{12}$ Because there are sex differences in trends in the prevalence of obesity and hypertension by age, the effects of WL on future BP increases may vary between men and women.

To prevent unfavorable outcomes due to hypertension in old age, it is necessary to examine the effects of WL on

Received May 25, 2020; accepted May 25, 2020; J-STAGE Advance Publication released online June 25, 2020 Time for primary review: 1 day

Department of Cardiovascular Medicine and Hypertension, Graduate School of Medical and Dental Sciences, Kagoshima University, Kagoshima (S.K., T. Kubozono, S.O., T. Kawabata, M.O.); Kagoshima Kouseiren Hospital, Kagoshima (H.M., K.T.), Japan

M.O. is a member of the Circulation Reports' Editorial Team.

Mailing address: Takuro Kubozono, MD, PhD, Department of Cardiovascular Medicine and Hypertension, Graduate School of Medical and Dental Sciences, Kagoshima University, 8-35-1 Sakuragaoka, Kagoshima 890-0075, Japan. E-mail: kubozono@m. kufm.kagoshima-u.ac.jp

All rights are reserved to the Japanese Circulation Society. For permissions, please e-mail: cr@j-circ.or.jp

ISSN-2434-0790 


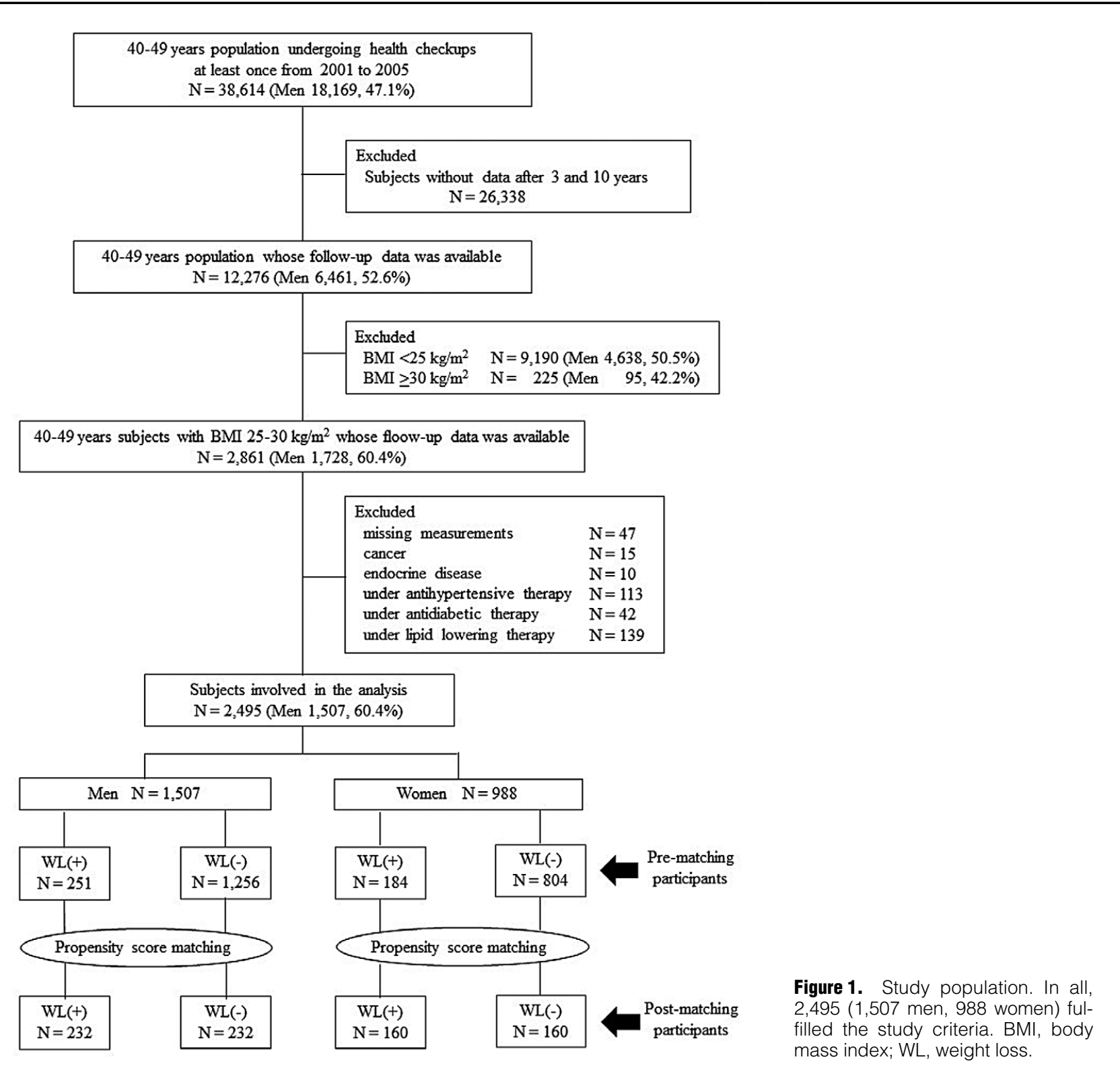

BP in middle-aged individuals. It is not always easy to assume the success of significant WL in daily clinical practice because even slight WL requires a strong will. In the present study we analyzed the health checkup data for a general Japanese population with the aim of investigating whether there were sex differences in the degree of BP increase and the prevalence of hypertension in the future following slight WL in middle-aged obese participants.

\section{Methods}

\section{Study Population}

Data from annual health checkups at Kagoshima Kouseiren Medical Healthcare Center (Kagoshima, Japan), collected from January 2001 through December 2015, were analyzed retrospectively. First, individuals who were aged in their 40s (age 40-49 years) and had had a health checkup at least once from 2001 to 2005 were identified. Among these individuals, those who underwent health examinations after both 3 years (range 2-4 years) and 10 years (range 9-11 years) were selected for inclusion in this study. To include only mildly obese individuals (BMI $25.0-29.9 \mathrm{~kg} / \mathrm{m}^{2}$ ), subjects with a baseline BMI $<25$ and $\geq 30 \mathrm{~kg} / \mathrm{m}^{2}$ were excluded. Individuals with missing variable measurements used for the matching of baseline characteristics or statistical analyses were also excluded, as were those with cancer and endocrine diseases, which may affect body weight or BP. Moreover, participants who were receiving medical treatment at baseline for hypertension, dyslipidemia, or diabetes were also excluded. The remaining individuals were included in the analysis.

This study was performed in accordance with the Declaration of Helsinki and was approved by the Institutional Ethics Committees of the Graduate School of Medical and Dental Sciences, Kagoshima University. 


\begin{tabular}{|c|c|c|c|c|c|c|c|}
\hline \multirow[b]{3}{*}{ Men } & \multicolumn{3}{|c|}{ Before matching } & \multicolumn{4}{|c|}{ After matching } \\
\hline & WL(+) & WL(-) & P-value & WL(+) & WL(-) & P-value & SD \\
\hline & & & & & & & \\
\hline No. subjects & 251 & 1,256 & & 232 & 232 & & \\
\hline Age (years) & $44.0 \pm 2.8$ & $44.1 \pm 2.8$ & 0.49 & $43.9 \pm 2.7$ & $43.8 \pm 2.8$ & 0.67 & 0.04 \\
\hline BMI $\left(\mathrm{kg} / \mathrm{m}^{2}\right)$ & $26.9 \pm 1.3$ & $26.6 \pm 1.2$ & $<0.001$ & $26.9 \pm 1.3$ & $27.0 \pm 1.4$ & 0.31 & 0.09 \\
\hline $\mathrm{SBP}(\mathrm{mmHg})$ & $124.8 \pm 15.8$ & $121.8 \pm 15.3$ & $<0.01$ & $123.7 \pm 15.0$ & $125.2 \pm 17.9$ & 0.33 & 0.09 \\
\hline $\mathrm{DBP}(\mathrm{mmHg})$ & $80.7 \pm 11.4$ & $79.4 \pm 11.2$ & 0.09 & $80.4 \pm 11.5$ & $81.0 \pm 12.8$ & 0.59 & 0.05 \\
\hline $\mathrm{TG}(\mathrm{mg} / \mathrm{dL})$ & $\begin{array}{c}156.5 \\
{[105,236.5]}\end{array}$ & $\begin{array}{c}157 \\
{[110,230.5]}\end{array}$ & 0.65 & $\begin{array}{c}153.5 \\
{[113.3,244.5]}\end{array}$ & $\begin{array}{c}155.5 \\
{[105,230]}\end{array}$ & 0.97 & 0.05 \\
\hline LDL-C (mg/dL) & $126.3 \pm 42.9$ & $123.2 \pm 39.3$ & 0.27 & $126.2 \pm 42.6$ & $125.1 \pm 47.1$ & 0.79 & 0.02 \\
\hline$B G(m g / d L)$ & $\begin{array}{c}104 \\
{[95,117.8]}\end{array}$ & $\begin{array}{c}100 \\
{[94,108]}\end{array}$ & $<0.001$ & $\begin{array}{c}103 \\
{[95,116]}\end{array}$ & $\begin{array}{c}103.5 \\
{[96,113]}\end{array}$ & 0.79 & 0.08 \\
\hline eGFR $\left(\mathrm{mL} / \mathrm{min} / 1.73 \mathrm{~m}^{2}\right)$ & $84.1 \pm 16.5$ & $81.1 \pm 13.7$ & $<0.01$ & $83.4 \pm 15.2$ & $82.0 \pm 14.3$ & 0.31 & 0.09 \\
\hline Smoker & $128(51.0)$ & $628(50.0)$ & 0.77 & $119(51.3)$ & $116(50.0)$ & 0.78 & 0.02 \\
\hline Usual drinker & $170(67.7)$ & $818(65.1)$ & 0.43 & $159(68.5)$ & $156(67.2)$ & 0.76 & 0.02 \\
\hline \multicolumn{8}{|l|}{ Women } \\
\hline No. subjects & 184 & 804 & & 160 & 160 & & \\
\hline Age (years) & $45.0 \pm 2.7$ & $44.7 \pm 2.8$ & 0.22 & $45.1 \pm 2.7$ & $45.0 \pm 2.7$ & 0.62 & 0.05 \\
\hline BMI $\left(\mathrm{kg} / \mathrm{m}^{2}\right)$ & $26.8 \pm 1.2$ & $26.7 \pm 1.3$ & 0.23 & $26.7 \pm 1.2$ & $26.7 \pm 1.3$ & 0.96 & $<0.01$ \\
\hline $\mathrm{SBP}(\mathrm{mmHg})$ & $118.5 \pm 14.8$ & $117.6 \pm 16.0$ & 0.51 & $118.6 \pm 15.1$ & $119.0 \pm 15.9$ & 0.82 & 0.02 \\
\hline $\mathrm{DBP}(\mathrm{mmHg})$ & $74.0 \pm 9.3$ & $73.7 \pm 10.3$ & 0.71 & $74.1 \pm 9.4$ & $73.4 \pm 9.9$ & 0.50 & 0.07 \\
\hline $\mathrm{TG}(\mathrm{mg} / \mathrm{dL})$ & $\begin{array}{c}84 \\
{[64,119]}\end{array}$ & $\begin{array}{c}90 \\
{[66,120]}\end{array}$ & 0.29 & $\begin{array}{c}86 \\
{[64.25,119.75]}\end{array}$ & $\begin{array}{c}83 \\
{[65,117]}\end{array}$ & 0.60 & 0.07 \\
\hline LDL-C (mg/dL) & $124.2 \pm 29.9$ & $123.4 \pm 30.8$ & 0.74 & $124.4 \pm 29.8$ & $126.7 \pm 32.0$ & 0.52 & 0.07 \\
\hline $\mathrm{BG}(\mathrm{mg} / \mathrm{dL})$ & $\begin{array}{c}97 \\
{[90,105]}\end{array}$ & $\begin{array}{c}95 \\
{[89,100]}\end{array}$ & $<0.01$ & $\begin{array}{c}97 \\
{[90,103.75]}\end{array}$ & $\begin{array}{c}95.5 \\
{[89,101]}\end{array}$ & 0.46 & 0.05 \\
\hline eGFR $\left(\mathrm{mL} / \mathrm{min} / 1.73 \mathrm{~m}^{2}\right)$ & $86.2 \pm 15.0$ & $85.6 \pm 16.2$ & 0.65 & $85.9 \pm 14.9$ & $84.5 \pm 15.8$ & 0.43 & 0.08 \\
\hline Smoker & $9(4.9)$ & $26(3.2)$ & 0.27 & $7(4.4)$ & $8(5.0)$ & 0.79 & 0.02 \\
\hline Usual drinker & $9(4.9)$ & $52(6.5)$ & 0.42 & $7(4.4)$ & $4(2.5)$ & 0.35 & 0.10 \\
\hline
\end{tabular}

Unless indicated otherwise, data are given as the mean $\pm \mathrm{SD}$, median [interquartile range], or $\mathrm{n}(\%)$. BG, blood glucose; $\mathrm{BMI}$, body mass index; DBP, diastolic blood pressure; eGFR, estimated glomerular filtration rate; LDL-C, low-density lipoprotein cholesterol; SBP, systolic blood pressure; SD, standardized difference; TG, triglyceride; WL, weight loss.

\section{Data Collection}

Body height and weight were measured by trained personnel using standard anthropometric techniques, and BMI was calculated as weight $(\mathrm{kg})$ divided by height squared $\left(\mathrm{m}^{2}\right)$. Information on cigarette smoking and alcohol consumption was obtained from self-administered questionnaires, and subjects were classified as follows: smoker, smoking currently; non-smoker, never smoked or past smoker; chance drinker, drinking $\leq 10$ days/month; and usual drinker, drinking $>10$ days/month. Data regarding diseases and current medications for hypertension, diabetes mellitus, and dyslipidemia were obtained using self-administered questionnaires. BP was measured after the participants had sat quietly for $5 \mathrm{~min}$. Blood samples were obtained from the patient after overnight fasting. Serum triglyceride (TG), low-density lipoprotein cholesterol, blood glucose (BG), and creatinine concentrations were determined using standard laboratory procedures. The estimated glomerular filtration rate (eGFR) was determined according to the new Japanese coefficient for the modified isotope dilution mass spectrometry-traceable Modification of Diet in Renal Disease study equation ${ }^{\mathbf{1 3}}$ as follows:

$$
\begin{aligned}
& \mathrm{eGFR}=194 \times \mathrm{SCr}^{-1.094} \times \mathrm{Age}^{-0.287}(\text { for males) } \\
& \mathrm{eGFR}=194 \times \mathrm{SCr}^{-1.094} \times \mathrm{Age}^{-0.287} \times 0.739 \text { (for females) }
\end{aligned}
$$

where $\mathrm{SCr}$ is the serum creatinine concentration.

\section{Grouping and Baseline Matching}

Participants were divided into 2 groups according to changes in BMI from baseline to the 3-year follow-up as follows: WL group, participants in whom BMI decreased $\geq 1.0 \mathrm{~kg} / \mathrm{m}^{2} ;$ non-WL group, participants who gained weight or lost no more than $1.0 \mathrm{~kg} / \mathrm{m}^{2}$.

Furthermore, propensity score (PS) matching was used to create a balanced distribution of baseline characteristics between the WL and non-WL groups. First, a logistic regression for WL was used to develop the PS for each participant. Variables such as age, BMI, smoking and drinking status, eGFR, systolic BP (SBP), diastolic BP (DBP), and hypertension (defined as $\mathrm{SBP} \geq 140 \mathrm{mmHg}$ and/or DBP $\geq 90 \mathrm{mmHg}$ ) at baseline were included for the calculation of the PS. A greedy nearest-neighbor matching algorithm with a caliper of width of $0.2 \mathrm{SD}$ of the logit of the PS was used. The balance of covariates between the WL and non-WL groups was assessed using absolute standardized differences, whereby an absolute standardized difference $>0.1$ represents meaningful imbalance. In order to keep the post-balancing assumptions at baseline, we did not exclude individuals who had cancer or endocrine disease in the follow-up period.

\section{Statistical Analyses}

Because the aim of this study was to investigate sex differences 

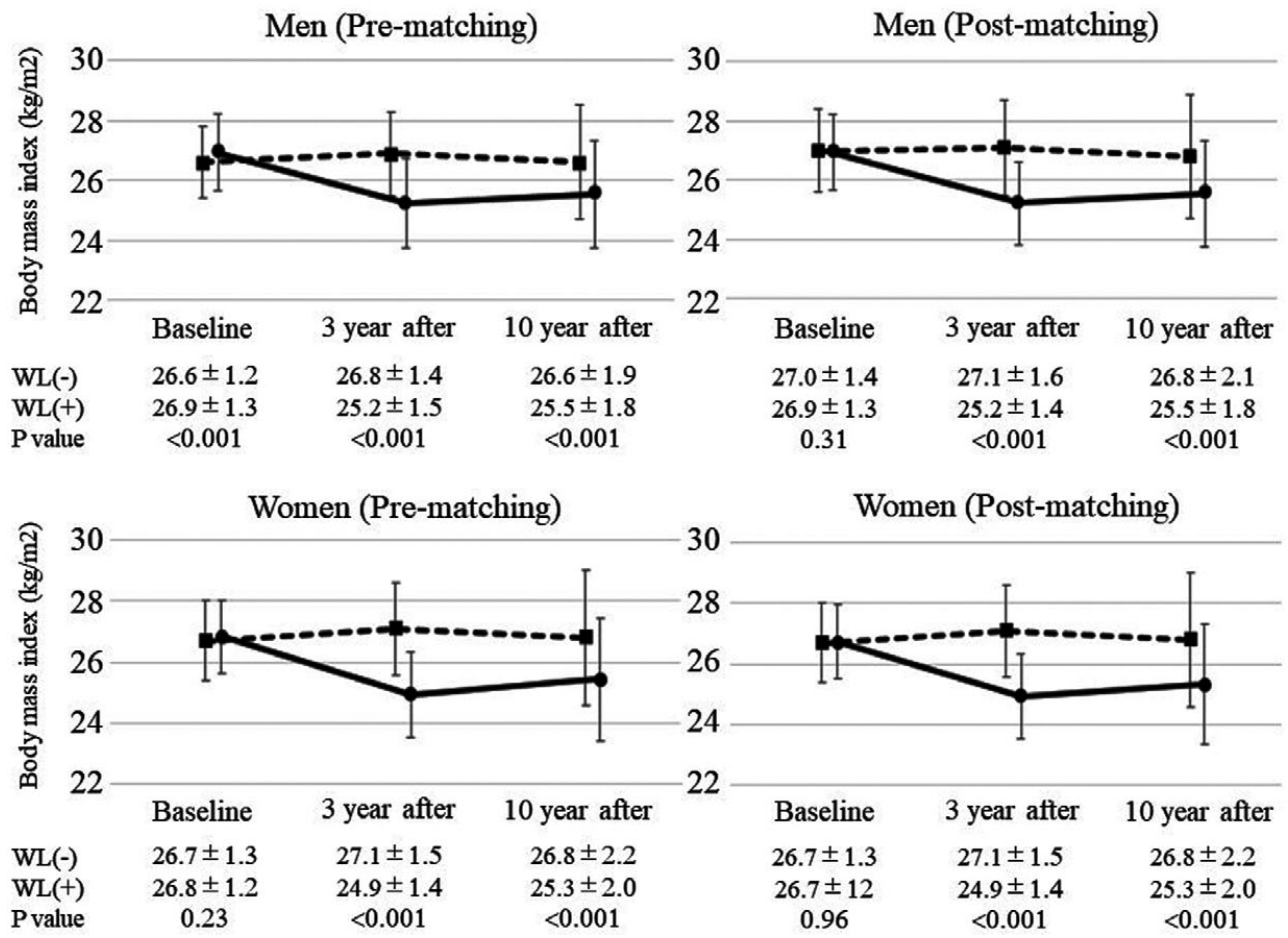

Figure 2. Changes in the body mass index (BMI) of participants before and after propensity score matching at baseline. The BMI at baseline and after 3 and 10 years was stratified according to weight loss (WL). Solid lines indicate changes in BMI in the WL group, whereas dashed lines indicate changes in BMI in the non-WL group. Data are presented for each sex separately and for participants before and after matching at baseline. Data are the mean \pm SD.

in the association between WL and hypertension, the grouping and analysis were performed separately for men and women. Continuous variables are expressed as the mean $\pm \mathrm{SD}$, except for $\mathrm{TG}$ and $\mathrm{BG}$, which are expressed as the median with interquartile range (IQR). Categorical variables are expressed as the number of participants and proportions (percentages). Sex differences in the baseline characteristics for continuous and categorical variables between the WL and non-WL groups were analyzed using unpaired t-tests (except for TG and BG, which were analyzed using the Wilcoxon test) and the $\chi^{2}$ test, respectively. BMI, SBP, and DBP were compared between the WL and non-WL groups at the 3- and 10-year follow-up time points. Finally, the prevalence of hypertension at the 10-year follow-up was compared between the WL and non-WL groups. Statistical analyses were performed on participants both before and after PS matching.

All statistical analyses were performed using JMP Pro version 14 for Windows (SAS Institute, Cary, NC, USA). Two-sided $\mathrm{P}<0.05$ was considered significant.

\section{Results}

\section{Baseline Characteristics of the Study Population}

Figure 1 shows the flow diagram of this study. In all, 38,614 individuals aged 40-49 years $(18,169$ men, $47.1 \%)$ had data for at least 1 health checkup from 2001 to 2005. Of these, data were obtained after 3 and 10 years for 12,276 subjects (men 52.6\%). Individuals with baseline BMI $<25 \mathrm{~kg} / \mathrm{m}^{2}(\mathrm{n}=9,190$; men $50.5 \%)$ and $\geq 30 \mathrm{~kg} / \mathrm{m}^{2}(\mathrm{n}=225$; men $42.2 \%$ ) were excluded. After excluding those individuals with missing measurements, with cancer or endocrine diseases, or those receiving medication for hypertension, diabetes, or dyslipidemia, there were 2,495 subjects remaining $(1,507$ men [60.4\%], 988 women [39.6\%]) for analysis in this study. After PS matching using baseline variables, data were analyzed from 464 men $(n=232$ each in the WL and non-WL groups) and 320 women $(n=160$ each in the WL and non-WL groups). Table presents the baseline characteristics by sex prior to and after matching. In the male population before matching, BMI, SBP, BG, and eGFR were significantly higher in the WL than non-WL group; in the female population before matching, BG was significantly higher in the WL than non-WL group. After matching, participants of both sexes in both groups were well balanced with regard to each baseline variable.

Changes in BMI, BP, and the Prevalence of Hypertension Changes in BMI from baseline to follow-up in the WL and non-WL groups for participants before and after PS matching are shown in Figure 2. For participants both before and after matching, BMI after 3 years was significantly lower in the WL than non-WL group, and this significant difference persisted even after 10 years among both men and women.

Changes in BP from baseline to the 10-year follow-up in the WL and non-WL groups are shown in Figure 3. In the male population before matching, DBP after 3 years was significantly lower in the WL than non-WL group (79.1 \pm 11.1 vs. $81.7 \pm 11.0 \mathrm{mmHg}$, respectively; $\mathrm{P}<0.001)$, 

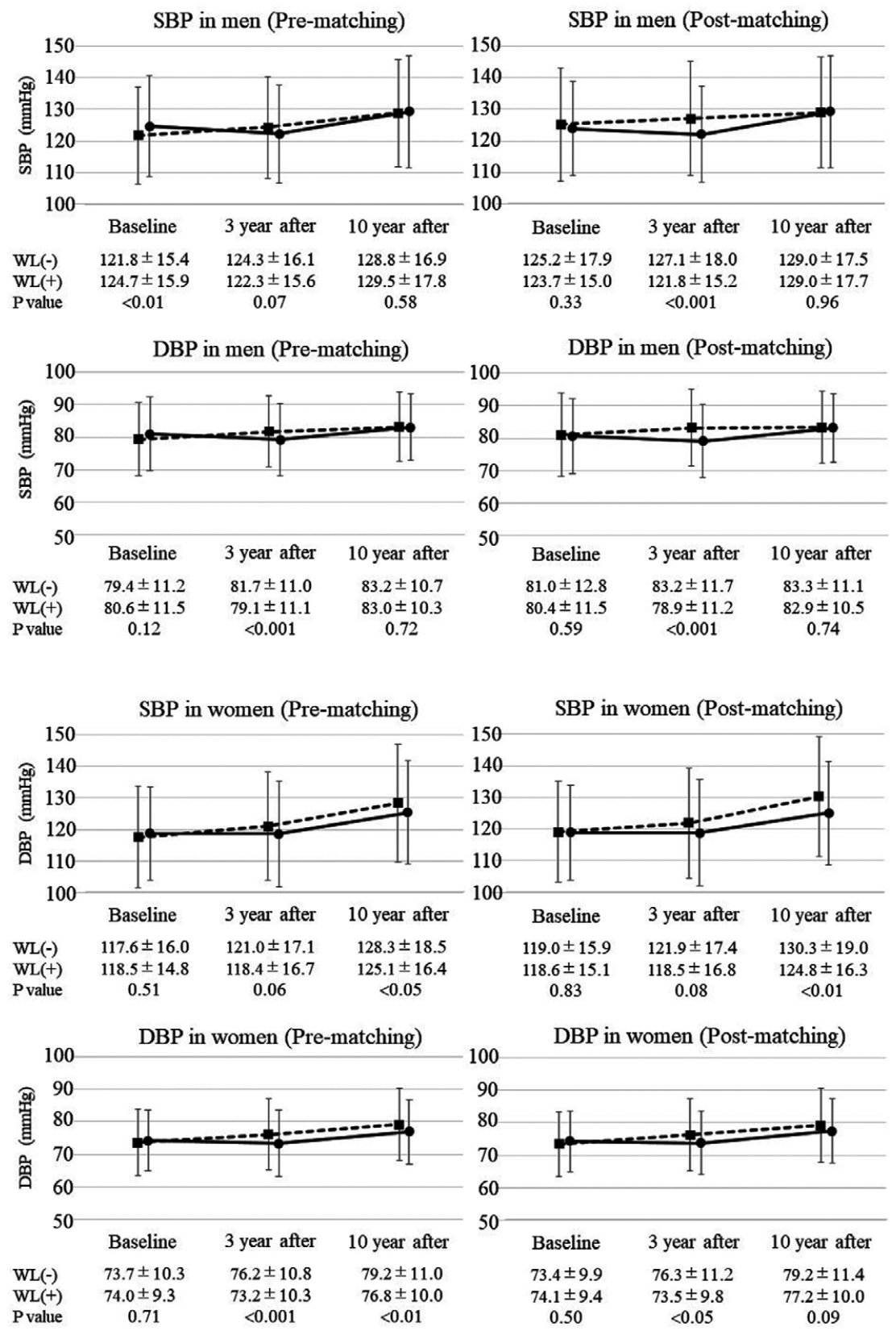

Figure 3. Changes in systolic and diastolic blood pressure (SBP and DBP, respectively) in participants before and after baseline matching. SBP and DBP at baseline and after 3 and 10 years were stratified according to weight loss (WL). Solid lines indicate changes in blood pressure in the WL group, whereas dashed lines indicate changes in blood pressure in the non-WL group. Data are presented for each sex separately and for participants before and after matching at baseline. Data are the mean $\pm S D$.

whereas there was no significant difference in SBP between the 2 groups. After 10 years, neither SBP nor DBP differed significantly between the WL and non-WL groups. In the male population after matching, the results were similar to those before matching, except that SBP after 3 years was significantly lower in the WL than non-WL group (121.8 \pm 15.2 vs. $127.1 \pm 18.0 \mathrm{mmHg}$, respectively; $\mathrm{P}<0.001)$.

In the female population before matching, DBP after 3 years was significantly lower in the WL than non-WL group (73.2 \pm 10.3 vs. $76.2 \pm 10.8 \mathrm{mmHg}$, respectively; $\mathrm{P}<0.001)$, whereas there was no significant difference in SBP. After 10 years, both SBP and DBP were significantly lower in the WL than non-WL group (SBP: 125.1 \pm 16.4 vs. $128.3 \pm 18.5 \mathrm{mmHg}$, respectively $[\mathrm{P}<0.05]$; DBP: $76.8 \pm 10.0$ vs. $79.2 \pm 11.0 \mathrm{mmHg}$, respectively $[\mathrm{P}<0.01])$. In the female population after matching, SBP after 10 years was significantly lower in the WL than non-WL group $(124.8 \pm 16.3$ vs. $130.3 \pm 19.0 \mathrm{mmHg}$, respectively; $\mathrm{P}<0.01)$, but there was no significant difference in DBP after 10 years between the 2 groups.

Figure 4 shows the prevalence of hypertension at the 10 -year follow-up in the WL and non-WL groups. In the analysis of the male population before and after matching, there were no significant differences in the prevalence of hypertension between the groups. However, a significant difference was found in the prevalence of hypertension between women in the WL and non-WL groups after matching (35.0\% vs. $48.1 \%$, respectively; $\mathrm{P}<0.05)$, but not before PS matching. 

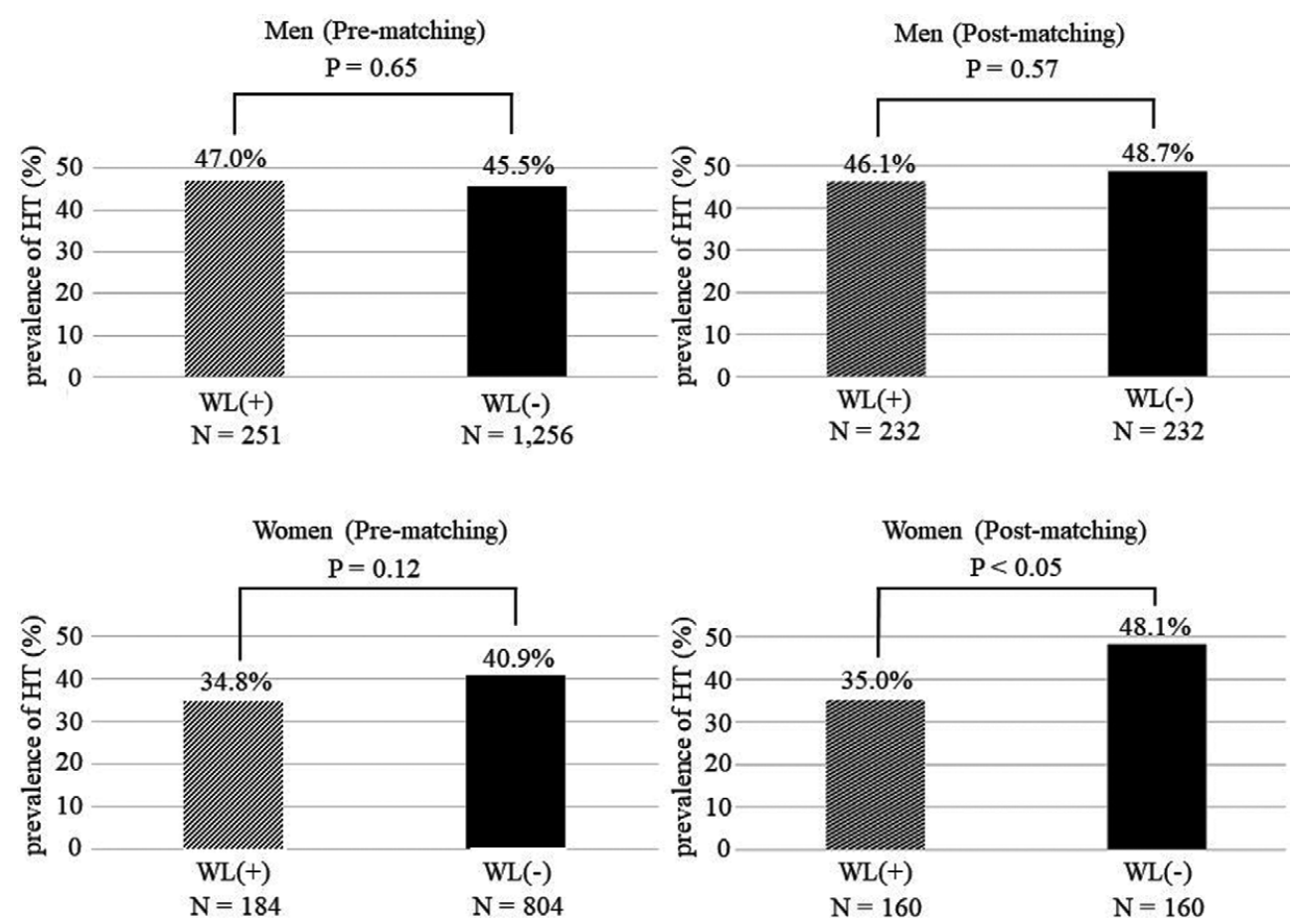

Figure 4. Prevalence of hypertension (HT) after 10 years with or without weight loss $(\mathrm{WL}(+)$ and $\mathrm{WL}(-)$, respectively). Data are presented for each sex separately and for participants before and after matching at baseline. Data are the mean $\pm S D$.

\section{Discussion}

In this study, subjects were divided into WL and non-WL groups according to changes in BMI from baseline to 3 years. Ten years after the baseline measurements, both men and women in the WL group in maintained significantly lower BMI than those in the non-WL group. Focusing on $\mathrm{BP}$ after 10 years, SBP and the prevalence of hypertension were significantly lower in women in the WL than non-WL group; in men, no differences were observed between the 2 groups. In middle-aged (40s) individuals with mild obesity, we observed sex differences in the long-term effects of slight WL on BP.

There are many reports regarding the association between obesity and hypertension. ${ }^{14-17}$ Visceral adiposity, ${ }^{18}$ an overactivated renin-angiotensin-aldosterone system, ${ }^{19}$ sympathetic nervous system enhancement, ${ }^{\mathbf{2 0}}$ the presence of sodium retention, ${ }^{21}$ insulin resistance and hyperinsulinemia, ${ }^{22}$ and the involvement of sleep apnea syndrome ${ }^{23}$ have been reported as causes for the development of hypertension due to obesity. It has also been reported that BP decreases according to WL. A previous report showed that a $2.4 \mathrm{~kg} / \mathrm{m}^{2}$ decrease in BMI by dietary therapy resulted in a $10 \mathrm{mmHg}$ decrease in SBP. ${ }^{24}$ In a study conducted in the Japanese population, WL $\geq 3 \%$ resulted in a significant decrease in BP. ${ }^{25}$ It is well recognized that diet is useful for suppressing hypertension in both men and women. Although previous studies reported the effects of suppressing BP by WL with a relatively short follow-up after WL, evidence for the long-term benefits of WL is lacking. Thus, the present study is novel because it revealed the effects of WL on BP with a relatively long-term follow-up period.
In the Japanese population, BP and the prevalence of hypertension consistently increase with age in both men and women.11 BMI and the prevalence of obesity have clear sex differences by age. In women, the prevalence of obesity is low for those in their $30 \mathrm{~s}$ and $40 \mathrm{~s}$, but begins to increase markedly after menopause and peaks in women in their $60 \mathrm{~s}$. In men, the prevalence of obesity increases from a young age and peaks in those in their $40 \mathrm{~s}$, gradually decreasing thereafter. ${ }^{12}$ When focusing on the same age, men and women may have different pathophysiology and lifestyles regarding obesity.

In the analysis of the male population before PS matching, BMI, SBP, and BG were significantly higher in the WL than non-WL group. These participants may be more motivated to lose weight due to concerns about future health problems. At the 3-year follow-up, both SBP and DBP were slightly decreased in the WL group and slightly increased in the non-WL group relative to baseline. At the 10 -year follow-up, there were no significant differences in SBP and DBP between the 2 groups. In the analysis of male population after matching, both SBP and DBP were significantly lower in the WL than non-WL group at the 3-year follow-up. However, there were no significant differences in SBP and DBP between the 2 groups at 10 years. In women, the baseline characteristics of the participants in the WL and non-WL groups were similar before matching, which indicates that these characteristics were not related to WL motivation. In the analysis of the female population both before and after PS matching, SBP was significantly lower in the WL than non-WL group after 10 years.

In this study the favorable effects of WL on BP persisted 
in women but disappeared in men after 10 years. Considering that differences in BMI still existed after 10 years, the result in men was surprising. There are several possibilities for this sex difference. BP is affected by several cardiovascular risk factors. In men, various cardiovascular risk factors begin to worsen starting at the age of 30 years. In contrast, in women, the metabolic cardiovascular risks are suppressed by the effects of estrogen until menopause, ${ }^{26}$ and lifestylerelated cardiovascular risks, including smoking and alcohol consumption, were fewer in women than in men. There is a possibility that the contribution of obesity to increases in $\mathrm{BP}$ is relatively larger in women because they have fewer cardiovascular risk factors than men. In general, when focusing on a particular cardiovascular risk, the effect of risk is often stronger in women..$^{27,28} \mathrm{BP}$ increases after menopause in women; ${ }^{29}$ therefore, the correction of obesity during perimenopause is important for preventing future BP increases in women. Furthermore, sex differences have been reported in vascular endothelial function and arterial stiffness. Vascular endothelial function evaluated by flowmediated dilation starts to decrease at 30-40 years of age in men, whereas the decrease is observed in women in their mid-50 s. ${ }^{30,31}$ Arterial stiffness evaluated by brachial-ankle pulse wave velocity (baPWV) showed a linear increase with age in men, whereas in women the degree of increase in baPWV was lower than in men and was not high with age until around 50 years. ${ }^{32}$ To prevent future increases in BP, WL around the age of 40 years may be too late in men. Earlier interventions may be necessary.

The present study has several limitations. First, the data were not collected prospectively; therefore, the results need to be verified in further prospective observational studies. Second, the participants were limited to those who underwent health checkups at a single facility in Japan. Furthermore, there is the potential of selection bias because the subjects in this study tended to have a deep interest in their health. Third, we did not collect any information on the actions taken for WL, such as dietary restrictions, exercise habits, oral medical treatment, surgery, and lifestyle improvement. However, because most oral and surgical treatments are not performed in Japan, most of the participants seem to have lost weight due to lifestyle improvements. Fourth, confounding factors related to BP, such as salt intake, vegetable and fruit consumption, exercise habits, stress, and sleep time, were not measured. Information on menopause in women, which may affect BP, was also not available. Finally, we did not consider indicators such as waist circumference or fat mass.

In conclusion, there were sex differences in the effectiveness of WL to prevent future increases in BP in mildly obese, middle-aged, Japanese participants. WL could prevent future BP increases and the onset of hypertension in women, but not in men.

\section{Acknowledgments}

The authors are grateful to the medical staff at Kagoshima Kouseiren Medical Health Care Center for support with data collection.

\section{Sources of Funding}

This study did not receive any specific funding.

\section{Disclosures}

M.O. is a member of Circulation Reports' Editorial Team. The other authors declare that they have no conflicts of interest.

\section{IRB Information}

This study was approved by the Institutional Ethics Committees of the Graduate School of Medical and Dental Sciences, Kagoshima University (No. 170130(520)).

\section{Data Availability}

The deidentified participant data will not be shared.

\section{References}

1. Poorolajal J, Hooshmand E, Bahrami M, Ameri P. How much excess weight loss can reduce the risk of hypertension? J Public Health (Oxf) 2017; 39: e95-e102.

2. Fantin F, Giani A, Zoico E, Rossi AP, Mazzali G, Zamboni M. Weight loss and hypertension in obese subjects. Nutrients 2019; 11: 1667.

3. Seravalle G, Grassi G. Obesity and hypertension. Pharmacol Res 2017; 122: $1-7$.

4. Susic D, Varagic J. Obesity: A perspective from hypertension. Med Clin North Am 2017; 101: 139-157.

5. Ho AK, Bartels CM, Thorpe CT, Pandhi N, Smith MA, Johnson HM. Achieving weight loss and hypertension control among obese adults: A US multidisciplinary group practice observational study. Am J Hypertens 2016; 29: 984-991.

6. Samadian F, Dalili N, Jamalian A. Lifestyle modifications to prevent and control hypertension. Iran J Kidney Dis 2016; 10: $237-263$.

7. Whelton PK, Carey RM, Aronow WS, Casey DE Jr, Collins KJ, Dennison Himmelfarb C, et al. 2017 ACC/AHA/AAPA/ABC/ ACPM/AGS/APhA/ASH/ASPC/NMA/PCNA guideline for the prevention, detection, evaluation, and management of high blood pressure in adults: Executive summary: A report of the American College of Cardiology/American Heart Association Task Force on Clinical Practice Guidelines [published errata appear in Hypertension 2018; 71: e33 and Hypertension 2018; 71: e136-e139]. Hypertension 2018; 71: 1269-1324.

8. Williams B, Mancia G, Spiering W, Agabiti Rosei E, Azizi M, Burnier M, et al. 2018 Practice guidelines for the management of arterial hypertension of the European Society of Cardiology and the European Society of Hypertension. Blood Press 2018; 27: 314-340.

9. Tanaka H, Kokubo Y. Epidemiology of obesity in Japan. Japan Med Assoc J 2005; 48: 34-41.

10. Yoshiike N, Matsushima S, Ito C, Ikeda Y, Kashihara H, Yoshinaga $\mathrm{H}$, et al. Obese degree and diabetes, hypertension based on body mass index, epidemiological examination - by associated - multicenter study with the risk factor of hyperlipidemia. $J J p n$ Soc Study Obesity 2000; 6: 4-17.

11. Miura K, Nagai M, Ohkubo T. Epidemiology of hypertension in Japan: Where are we now? Circ J 2013; 77: 2226-2231.

12. Yamakita M, Uchida H, Kawamura K, Homma T, Odagiri Y. Effects of age, period, and cohort on the trends in obesity rate and energy intake ratio from fat in Japanese adults. Jpn J Public Health 2014; 61: 371-384.

13. Matsuo S, Imai E, Horio M, Yasuda Y, Tomita K, Nitta K, et al. Revised equations for estimated GFR from serum creatinine in Japan. Am J Kidney Dis 2009; 53: 982-992.

14. Chei CL, Iso H, Yamagishi K, Tanigawa $\mathrm{T}$, Cui R, Imano H, et al. Body fat distribution and the risk of hypertension and diabetes among Japanese men and women. Hypertens Res 2008; 31: $851-857$.

15. Tsujimoto T, Sairenchi T, Iso H, Irie F, Yamagishi K, Tanaka $\mathrm{K}$, et al. Impact of obesity on incident hypertension independent of weight gain among nonhypertensive Japanese: The Ibaraki Prefectural Health Study (IPHS). J Hypertens 2012; 30: $1122-$ 1128.

16. Chen PC, Sung FC, Su TC, Chien KL, Hsu HC, Lee YT. Two-year change in body mass index and subsequent risk of hypertension among men and women in a Taiwan community. J Hypertens 2009; 27: 1370-1376.

17. Shuger SL, Sui X, Church TS, Meriwether RA, Blair SN. Body mass index as a predictor of hypertension incidence among initially healthy normotensive women. Am J Hypertens 2008; 21: 613-619.

18. Zachariah JP, Hwang S, Hamburg NM, Benjamin EJ, Larson MG, Levy D, et al. Circulating adipokines and vascular function: Cross-sectional associations in a community-based cohort. Hypertension 2016; 67: 294-300. 
19. Engeli S, Sharma AM. The renin-angiotensin system and natriuretic peptides in obesity-associated hypertension. $\mathrm{J} \mathrm{Mol} \mathrm{Med} \mathrm{(Berl)}$ 2001; 79: $21-29$

20. Grassi G, Pisano A, Bolignano D, Seravalle G, D'Arrigo G, Quarti-Trevano F, et al. Sympathetic nerve traffic activation in essential hypertension and its correlates: Systematic reviews and meta-analyses. Hypertension 2018; 72: 483-491.

21. Hall JE. Mechanisms of abnormal renal sodium handling in obesity hypertension. Am J Hypertens 1997; 10(Suppl 1): 49S-55S.

22. Sironi AM, Gastaldelli A, Mari A, Ciociaro D, Positano V, Buzzigoli E, et al. Visceral fat in hypertension: Influence on insulin resistance and beta-cell function. Hypertension 2004; 44: $127-133$.

23. Floras JS. Hypertension and sleep apnea. Can J Cardiol 2015; 31: 889-897.

24. Straznicky NE, Lambert EA, Nestel PJ, McGrane MT, Dawood T, Schlaich MP, et al. Sympathetic neural adaptation to hypocaloric diet with or without exercise training in obese metabolic syndrome subjects. Diabetes 2010; 59: 71-79.

25. Muramoto A, Matsushita M, Kato A, Yamamoto N, Koike G, Nakamura M, et al. Three percent weight reduction is the minimum requirement to improve health hazards in obese and overweight people in Japan. Obes Res Clin Pract 2014; 8: e466-e475.

26. Arai H, Yamamoto A, Matsuzawa Y, Saito Y, Yamada N,
Oikawa $\mathrm{S}$, et al. Serum lipid survey and its recent trend in the general Japanese population in 2000. J Atheroscler Thromb 2005; 12: $98-106$

27. Høieggen A, Alderman MH, Kjeldsen SE, Julius S, Devereux RB, De Faire U, et al. The impact of serum uric acid on cardiovascular outcomes in the LIFE study. Kidney Int 2004; 65: 1041-1049.

28. Kawasoe S, Kubozono T, Yoshifuku S, Ojima S, Miyata M, Miyahara $\mathrm{H}$, et al. Uric acid level and new-onset atrial fibrillation in the Japanese general population: Longitudinal study. Circ J 2018; 83: $156-163$.

29. Lima R, Wofford M, Reckelhoff JF. Hypertension in postmenopausal women. Curr Hypertens Rep 2012; 14: 254-260.

30. Skaug EA, Aspenes ST, Oldervoll L, Mørkedal B, Vatten L, Wisløff $U$, et al. Age and gender differences of endothelial function in 4739 healthy adults: The HUNT3 fitness study. Eur J Prev Cardiol 2013; 20: $531-540$

31. Celermajer DS, Sorensen KE, Spiegelhalter DJ, Georgakopoulos $\mathrm{D}$, Robinson J, Deanfield JE. Aging is associated with endothelial dysfunction in healthy men years before the age-related decline in women. J Am Coll Cardiol 1994; 24: 471-476.

32. Tomiyama H, Yamashina A, Arai T, Hirose K, Koji Y, Chikamori $\mathrm{T}$, et al. Influences of age and gender on results of noninvasive brachial-ankle pulse wave velocity measurement: A survey of 12517 subjects. Atherosclerosis 2003; 166: 303-309. 